\title{
Factors influencing male participation in reproductive health: a qualitative study
}

This article was published in the following Dove Press journal: Journal of Multidisciplinary Healthcare

\author{
Sumitra Sharma' \\ Bhuvan $\mathrm{KC}^{2}$ \\ Asmita Khatri ${ }^{3}$ \\ 'Department of Nursing, Kathmandu \\ Medical College Teaching Hospital, \\ Kathmandu, Nepal; ${ }^{2}$ School of \\ Pharmacy, Monash University Malaysia, \\ Subang Jaya, Malaysia; ${ }^{3}$ Bachelor of \\ Science in Nursing, Department of \\ Nursing, Kathmandu Medical College \\ Teaching Hospital, Kathmandu, Nepal
}

Correspondence: Sumitra Sharma Department of Nursing, Kathmandu Medical College Teaching Hospital, 184 Baburam Acharya Sadak, Sinamangal, Kathmandu, P.O. Box: 21266, Nepal Tel +977984 I56 257।

Email smtrsharma@gmail.com
Introduction: Male involvement in reproductive health is an essential component in promoting maternal and family health. In Nepal, men are not actively engaged in most maternal and child health $(\mathrm{MCH})$ services nor in other reproductive health programs. There is a need to know about the understanding of key professionals in such practices. This study explores gendered perspectives among teachers and health professionals to understand the factors contributing to male involvement in reproductive health.

Methods: The data were collected through two focus group discussions (FGDs) and seven key informant interviews (KIIs). FGDs were held among male teachers of selected schools, and KIIs were conducted with health professionals of the health post of Bungamati, Lalitpur. An unstructured interview guide was used to explore their experiences and perceptions. All KIIs and FGDs were recorded, translated and transcribed verbatim.

Results: Findings show limited male involvement in reproductive health. Participants reported several hindering and challenging factors such as sociocultural and psychological norms, lack of education, and misinformation and dominance of female as health care providers in many $\mathrm{MCH}$ clinics. Perceived motivating factors included positive attitude in men, literacy and awareness, inclusion of reproductive health in school curriculum and certain incentives. Participants also recommended a range of strategies for increasing men's involvement in reproductive health in Nepal.

Conclusion: Men's education and attitude, knowledge and awareness, sociocultural factors, psychological factors, health system factors, and policies play important roles in male involvement in reproductive health. Programs on effective implementation of men involvement in reproductive health initiatives should address the barriers and challenges to men's supportive activities. This study also suggests increasing literacy of reproductive health among men that enhances their positivity and motivates them to participate in reproductive health services.

Keywords: male participation, maternal and child health, reproductive health

\section{Introduction}

Although the data in maternal death show declining trend over the last three decades in developing countries, it still accounts for $99 \%$ of global maternal mortality in low- and middle-income countries, which approximates to 287,000 per year. ${ }^{1}$ Many international communities are putting their optimum efforts in reducing maternal mortality. Institutional delivery, universal access to antenatal care, presence of skilled health personnel during delivery and provision of essential equipment, drugs, and supplies are some of the important strategies that are being put forward. ${ }^{2}$ However, in recent years along with these potential drivers, male involvement in reproductive health is 
recommended as one of the basic interventions to improve the maternal health and outcomes. ${ }^{3,4}$

In most of the developing countries, men play the role of gatekeepers to health care..$^{5}$ They are the primary decision makers that directly affect their partner's and children's health. ${ }^{6}$ Their decisions affect in utilization of resources and access to health care services, use of contraceptives and child spacing, availability of nutritious food and women's workload. ${ }^{7}$ Apart from the role of decision makers in the family, their actions in terms of abuse or neglect have a direct impact over the health of their partner's and children. ${ }^{8}$ Thus, having tremendous economic and social power in the family, active involvement of men in maternal and child health $(\mathrm{MCH})$ has significant implications. However, in spite of significant role of men, they have inadequate knowledge about $\mathrm{MCH} .{ }^{9}$ The deep-rooted social structures of developing societies have formed an inequity over the power of making decision on various aspects of reproductive health. ${ }^{10}$ Furthermore, when men used to be the sole income generator of the family, their attention toward family health and their involvement in reproductive health is limited. ${ }^{11}$ This has led women to be the basic target in most of the health education and awareness programs and men tend to be excluded. ${ }^{12}$ This exclusion indicates an incredible reason behind men being unable to make informed decisions during emergencies and being less interested to engage in maternal and reproductive health. ${ }^{6}$

While the outlets of maternal health services are growing, lack of men's support for the utilization of safe motherhood services is seen as a barrier by the women. ${ }^{13}$ Historically, men engagement has been depicted as obstructive or nonexistent in reproductive health matters. They either impede on women's choice on the use of family planning methods or become nonresponsive due to lack of interest. ${ }^{14}$ There is also a practice for women to be assisted with the family members of same sex during labor. ${ }^{15}$ Also, the community where men are relatively less involved in HIV/AIDS prevention strategies have experienced an increase in sexually transmitted infections (STIs). ${ }^{13}$

There is a need for holistic approach for the involvement of men in reproductive health. If men and women are perceived as equal partners, effective decision making and better outcome in SRH can be expected. ${ }^{16}$ Consequently, many of the reproductive health programs have looked at addressing several issues through this gender lens. Numerous programs have tested men's involvement in various contexts and found to be positive in a number of areas, including family planning, ${ }^{17,18}$ prevention of HIV, ${ }^{19}$ birth preparedness and access to emergency obstetrics, women's workload during pregnancy and in raising emotional support and communication. ${ }^{6,20}$ In spite of enough evidences of the significance of male participation in reproductive health and their low level of involvement, less is known regarding the in-depth understanding over the factors related to this in Nepal. To address this gap, this study examines gendered perspective opinion among teachers and health professionals to explore several factors contributing to male involvement in reproductive health.

\section{Material and methods Study design}

This research is based on a qualitative method comprising key informant interviews (KIIs) and focused group discussions (FGDs). The study was conducted in Bungamati, Lalitpur district, Nepal, from July to September 2017. Bungamati is village that is located $10 \mathrm{~km}$ south of Kathmandu city, the capital of Nepal. It constitutes 1,304 total households with an average household size of 4.58 and total population of 5,966 , of which 3,575 are $15-49$ years old.

\section{Data collection}

KIIs with health care providers and FGDs with the teachers group were used to collect data. Health care providers and teachers were chosen because they are among the most important influencers in the lives of community people. Besides health professionals in a small community like Bungamati, teachers are key resource persons with whom confined information in several health issues can be ruled out rightly. Moreover, with the assumption that male teachers can relate with their experiences on discussing over the factor that have limited or facilitate for their participation in reproductive health, male teachers were selected for FGDs. Therefore, to complement FGDs and to examine the phenomenon under study from community health perspective, KIIs were conducted with health care providers of the same locality.

\section{Interview guide}

The interview guide consisted of two parts: the first part was sociodemographic information of the participants and the second part consisted of open-ended questions. Sociodemographic division included the information on age, sex, marital status, level of education, and number of children. However, the open-ended questions were used for KIIs and FGDs. An interview guide was first developed in English and later translated into Nepali language. 


\section{Sampling and recruitment}

Two schools (Divya Jyoti Secondary School and Tri-Ratna Higher Secondary School) of Bungamati, Lalitpur, were randomly chosen for conducting FGDs with the male teachers. Once the schools were chosen, a few visits were made by the researcher to meet with the principal and the main coordinator of the selected schools to inform them about the purpose of the study and the particular date and time for conducting FGDs. Purposive sampling was applied to recruit male teachers from the selected schools. To adequately represent the participation, FGDs were planned during an hour of break time. However, the health care providers of the health post are the key informants in the study. Census method was applied among health care providers to get their responses. All the health care providers were informed about the purposes of the study and all of them agreed to participate in the study. Nevertheless, there were no any forms of incentives for the participation.

\section{Role of selection bias}

In order to not let selection bias happen, we select the subject randomly even though research site was selected purposively. It is because it was both feasible for carrying out research as it was near Kathmandu and the area is a rural area with agropastoral way of life. However, the researcher did not know about the subjects of both KIIs and FGDs. The health post workers and school teachers were invited for an interview, and those who agreed were interviewed for the study

\section{Key informant interviews}

Seven in-depth interviews with individual key informants of the health facility were conducted. The interview was carried out separately in the closed room by the researcher, starting with the head of the health facility. The interview sessions lasted for about 35-45 minutes. All interviews were taperecoded. However, to supplement the transcripts, the research assistant took notes during each interview.

\section{Focus group discussions}

Two FGDs were conducted, and both were among the male teachers of the selected schools. In one FGD, there were six participants, and in other there were seven. The date were scheduled 10 days in advance and were notified to all the participants two times in between, because of which the desired number of participants was present for FGDs.

Before the beginning of each FGDs session, the purpose of the study was explained to each participant. When all the participants agreed to take part in the discussion, the session was formally started. Considering adequate privacy, silence and adequate lighting, the site for FGDs was selected. The participants were positioned in $\mathrm{C}$ shape inside the room. The principal investigator (PI), as a moderator, and research assistant stayed at the front so that everyone would be visible to everybody in a comfortable manner. The participants were encouraged to interact with each other and some probing questions were used by the PI to make the discussion more effective. Each session lasted for about 60-90 minutes. All discussions were tape-recoded. However, to supplement the transcripts, the research assistant also took notes.

\section{Data analysis}

Tape-recorded discussions and interviews were first transcribed into Nepali language, which was later translated into English language. The researchers then read the transcripts and field notes, word by word and started coding the data. Initial coding was made on the translated scripts. The translation of the interview from Nepali into English was verified from an expert of Nepali-English translator. The transcribed data were imported into the NVivo8 software, where coding was done and content analysis was performed. During the coding process, data were continuously reviewed, emerging patterns were noted and relationship between constructs was identified. Especially in FGDs, the author systematically analyzed explaining similar and contrasting viewpoints surrounding each theme.

\section{Ethical considerations}

The study was approved by Institutional Review Board of Kathmandu Medical College (Ref:17032017). Permission to conduct the study was obtained from the administration head of municipality office and in-charge of health post of Bungamati, Lalitpur district. The written consent was taken after explaining objectives of the study to the individual participant. However, to ensure the confidentiality of the information, respondents' names were not used in the field notes and audiotapes.

\section{Results \\ Demographic characteristics of study participants \\ Focus group discussions}

Thirteen participants took part in two FGDs. All of them were male. Two participants were less than 25 years of age. The age groups of 25-35 years and 35-45 years had five participants each. Only one participant was above 45 years. Except one respondent, everyone was married. Majority 
of the participants had one to two children. While almost half of them had completed master's degree, other half of the participants were educated up to higher secondary and bachelor's level (Table 1).

\section{Key informant interviews}

There were in total seven respondents. Four of the seven respondents were female and three were male. The age group 36-45 years had the most representation with four participants. Two of the participants were in the age group 25-35 years and only one above 45 years of age. All of them were married. Similar to FGDs, a large majority of KIIs participants had one to two children. However, contrary to FGDs, none of them were educated up to master's degree. Four of them had completed only up to higher secondary, and three of them had passed bachelor's level (Table 1). In addition, although there were both males and females in the KIIs, there were no differences in opinion with regard to gender.

\section{Knowledge and benefit of involving men in reproductive health}

"They should actively participate in family planning, care of pregnant lady and nutrition."

There was a broader understanding and acceptance among the respondents that men should play an active role in

Table I Characteristics of study participants for FGDs and KIls

\begin{tabular}{|l|l|l|}
\hline Variables & $\begin{array}{l}\text { Focus group } \\
\text { discussions }(\mathbf{n}=\mathbf{I} 3)\end{array}$ & $\begin{array}{l}\text { Key informant } \\
\text { interviews }(\mathbf{n}=7)\end{array}$ \\
\hline Age (years) & & \\
$<25$ & 2 & 0 \\
$25-30$ & 2 & 1 \\
$3 \mathrm{I}-35$ & 3 & $\mathrm{I}$ \\
$36-40$ & 4 & 2 \\
$4 \mathrm{I}-45$ & $\mathrm{I}$ & 2 \\
$>45$ & $\mathrm{I}$ & 1 \\
Sex & & \\
Female & 0 & 4 \\
Male & 13 & 3 \\
Marital status & & \\
Married & 12 & 7 \\
Single & 1 & 0 \\
No. of children & & \\
I-2 & 9 & 6 \\
Three or more & 3 & \\
Level of education & & 4 \\
Up to higher secondary & 3 & 3 \\
Bachelor's level & 4 & 0 \\
Master's degree & 6 & \\
\hline
\end{tabular}

Abbreviations: KIls, key informant interviews; FGDs, focused group discussions. maternal and child care. However, in terms of when and how men need to be involved in $\mathrm{MCH}$, the respondents gave varied answers. The teachers' groups said that man should be involved in different activities such as counseling, family planning, and taking care when the wife is sick and after 5 months of pregnancy.

The health care providers said that health and safety of mother and child is the reason why men accompany wife during pregnancy and child growth monitoring. However, they said that very few males accompany their wife to health facility for follow-up and in other $\mathrm{MCH}$-related activities.

The health care providers also said that they were of the view that males' involvement bring knowledge to the family, which then helps the husband to take care of his wife during pregnancy. They noted that educated men are mostly involved in wife's care and often accompany them to the $\mathrm{MCH}$ clinics

\section{Factors hindering male involvement in reproductive health}

The teachers' group said that sociocultural factors like patriarchal family, generation gap among family members, having male as a solo income generator and female preferences to go by themselves for $\mathrm{MCH}$ services might have hindered male from accompanying wife in $\mathrm{MCH}$ clinics.

\footnotetext{
"Mostly males are involved in income-generation; they don't have enough time and have to take days off."
}

Furthermore, the health care providers were of the view that religious factors, village life and social prestige of men and negative perception of society too hinder them from accompanying wife in $\mathrm{MCH}$ clinics and in family planning activities.

As per the teachers group, psychosocial factors such as individual mind set and shyness might have hindered male from accompanying their wife in $\mathrm{MCH}$ clinics. They were of the view that these factors were linked with education and awareness of the male member of the society.

Remarkably, both the group of respondents identified specific health system factors as barriers to reproductive health. Availability of Female Community Health Volunteers (FCHVs) and nurse in most of the health facility prefer female clients to talk about health issues and defer to talk when they encounter with male, visiting health care facility with issues of $\mathrm{MCH}$ services and reproductive health.

In addition, both the health care providers' and teachers' groups identified misinformation as the challenge men face when getting involved in the care of pregnancy and childbirth. They said that the information of vasectomy is misunderstood 
by many of the people in this community. They think that vasectomy can cause back pain, weakness and have problems in erection following surgery.

"There was a case of vasectomy failure in my locality. The male had surgery after having two children. After surgery too, he had two more children. Later his wife did Minilap."

Lack of knowledge about condom use and other family planning methods, and problems with disposal of condom are the challenges that men face if they want to be involved in pregnancy and child birth.

\section{Factors motivating male involvement in reproductive health}

The teachers' group mostly said that the feeling of responsibility motivates men to involve in various reproductive health activities. They also identified that positive attitude in men can inspire them to accompany their wife in family planning and $\mathrm{MCH}$ services. They were also of the view that if men are involved in future planning of their children, show love and care, then it might persuade them in making good decision for the use of effective contraceptives and support the wives in maintaining balanced sexual life.

Education was also identified as the other motivating factor. They mentioned that literate men make the effective informed choices especially during the emergency when one's decision play a vital role. Furthermore, they also identified awareness as the factor that compliments the educational background of the men. They also said that their action for safer sex, planned pregnancy and accompanying their wife for $\mathrm{MCH}$ clinics might also aware their neighbor and motivate them to follow such actions.

"If I go with my wife, my neighbours will also imitate that behaviour."

However, the health care providers said that the fact that health status is difficult to recover after degradation of person's health and the cost associated with the treatment of sickness might be the factor that drive men to support wives in making reproductive health care decisions. Furthermore, the health care providers also recognized that involvement in $\mathrm{MCH}$ activities is responsibility of both male and female. Therefore, this sense of responsibility might also inspire men to be aware of sexual and reproductive health activities between the couple, including children immunization and their health.

The teachers' group identified the need for more education and awareness program so that men get motivated and get involved in $\mathrm{MCH}$ clinics and in family planning. They also felt the need to include $\mathrm{MCH}$ in the school curriculum. They also talked about the effect of incentive on males' involvement.

"Few years back when AAMA MILAN KENDRA ran a project on Role of males in $\mathrm{MCH}$ along with provision of incentives, the outcome (male participation) was found impressive."

\section{Sexually transmitted diseases (STDs) and male involvement in reproductive health}

The teachers' group was of the view that there is a relation between male involvement in reproductive health and STDs like HIV/AIDS. They said that if men participate in different reproductive health activities like contraception usage, planning of family and have safe sex, it certainly helps to prevent STDs. Although they told that male involvement plays a major role, they also recognized the fact that both male and female should be involved in reproductive health

"In Nepali society, males play major role in $\mathrm{RH}$, so they

should be involved. But involvement of male alone is not enough, female should also be involved."

However, some respondents were of the view that husband would know about STDs like HIV/AIDS and they are alert by themselves.

The health care providers said that the male partner would adopt safer sex practice if they were involved in $\mathrm{MCH}$ and family planning activities. Furthermore, they were of the view that STIs should be treated in time.

"STIs should be treated in time."

\section{Recommendation for better male involvement in reproductive health}

In both groups, the respondents were of the view that both male and female are responsible, and both need to play a vital role in contraceptive devices use. But they were also mindful that differences exist in adopting permanent means and the family need to consult the doctor for the choice of suitable family planning devices and for proper child spacing.

The respondents said that males are better suited for using contraceptive devices as it is easy for males to use and possess less side effect to them. However, they also recognized the fact that there are fewer options for men and sometimes they are reluctant to use condoms.

"For e.g. condom if used by male is lot easier than female." 
Some respondents also said that females should use the contraceptive devices as more options exists for them.

"Females more responsible in Tamang community for contraceptive usage while males are also sharing the responsibility in Newar and Chhettri community"

The health care providers identified an interesting fact about the ethnic difference in the way male and females get involved in $\mathrm{MCH}$ and reproductive health activities. For example, they said that the females are responsible in Tamang community while males are also sharing responsibility in Newar and Chhettri community.

Furthermore, the health care providers also said that there is a need for policies that promote both husband and wife to visit the health facilities for antenatal and postnatal care.

\section{Discussion}

This study explores details about the experiences of the male teachers and staffs of health care facility toward the factors influencing involvement of the husband during pregnancy, child birth, family planning, and in other male and female reproductive health issues. Although there are many determinants contributing to SRH indicators, low level of male participation is a major factor. While there have been some previous studies on perspectives from local people and community workers, this study is the first of its kind in Nepal, bringing together the experiences and perceptions from the known stakeholders of the community. The findings, therefore created more profound understanding and complement other similar quantitative studies exploring several factors responsible for male involvement in reproductive health.

This study shows that there is a broader understanding among the respondents about the determinants influencing male participation in reproductive health. The respondents said that the issue of health and safety of mother and child is the important element behind men's involvement in $\mathrm{MCH}$ activities. A study by Lewis et al in Gorkha district of Nepal too shows that the expectant father has important role in maternal health and safe childbirth. ${ }^{9,11}$ Men's involvement in $\mathrm{MCH}$ and reproductive health activities was bringing knowledge that was helpful for the family in dealing with similar activities and men's involvement was related to their educational background. As suggested by Lewis et al's study from Gorkha, Nepal, men's involvement in maternal health and childbirth related activities is a complex issue that is linked to education and changing dynamics of the society. However, what is concerning is that the health care providers reported that very few males accompany their wife during pregnancy and follow-up visited and other $\mathrm{MCH}$-related activities so there is need to understand the dynamics of male involvement in $\mathrm{MCH}$ activities in Nepal and deliver positive interventions accordingly. ${ }^{11}$

As per the respondents, sociocultural and socioeconomic factors such as patriarchal family structure, generation gap, male as income generator, female preference to go for $\mathrm{MCH}$ activities by themselves, religious factor, village life and negative perception of society hindered men's involvement in $\mathrm{MCH}$ activities. A study by Kaye et al in Uganda shows that men who accompany wife to hospital also identified factors such as personal relationship, family and community as the hurdles to their involvement during childbirth. ${ }^{21}$ Likewise, health system factors such as the FCHVs and nurse not allowing men involvement in $\mathrm{MCH}$ clinics, family planning and $\mathrm{MCH}$ services being run by female health care providers favoring females, misinformation about contraceptive methods and means, and a general health facility environment that doesn't support and promote men were the factors hindering male involvement. Several studies have identified health system as unwelcoming, uncooperative and intimidating for male involvement in $\mathrm{MCH}$, childbirth and other activities. ${ }^{21,22}$ There seems to be dual challenges related to societal factors and health system factors when it comes to male involvement in $\mathrm{MCH}$, during childbirth and reproductive health activities. Thus, the strategies must be multidimensional and should target education, awareness and socioeconomic aspect as societal level and quality and service delivery of antenatal care, delivery and postnatal healthcare services, male and female reproductive health issues and male friendly at the hospital level. ${ }^{11,21,23}$

As per our research, male involvement in reproductive health is linked with societal and health system dynamics. Although, some factors hinder men's involvement in $\mathrm{MCH}$ and reproductive health in community level, the feeling of responsibility, education and positive attitude motivates men's involvement in reproductive health activities. A study by Kululanga et al in Malawi discusses about various strategies that utilize social factors that can promote men's participation in maternal health care. ${ }^{11}$ However, the study also reports about using different strategies for urban and rural residents and those who are educated or lack in education. Interestingly, the healthcare providers in our study highlighted the case of ethnic differences in male and female involvement in reproductive health activities which too have to be accommodated when developing programs that promotes men's involvement in several reproductive health activities. The health system dynamics too is a complex thing as it encompasses multiple 
factors in demand and supply of the services. In the supply side, it includes factors such as quality and delivery of $\mathrm{MCH}$ services, availability of different type of family planning options and male supportive health facilities. Likewise, in the demand side, factors like utilization of such services, misinformation, male participation and so on are included. In our study too, the respondents reported about the positive effect of incentive on male involvement in $\mathrm{MCH}$ activities and the widespread misconception about vasectomy and other family planning methods that is affecting male usage of these services. Studies have reported about the effects of demandside interventions on maternal care, maternal and infant mortality and have said that these interventions can increase utilization of services and reduce mortality. ${ }^{24,25}$ Furthermore, there is the issue of linkage between reproductive health and STIs, such as HIV/AIDS. Thus, the interventions and policies to improve male involvement in reproductive health activities must be suitable to the local context, should address broader population's need and the availability of resources.

\section{Conclusion}

The factors that can influence the degree of male participation in reproductive health can vary from several perspectives in which individual live and interact. This study concludes that men's education and attitude, knowledge, and awareness, sociocultural factors, psychological factors, heath system factors, and policies play important roles in male involvement in reproductive health. Given a complete understanding on the need of more male participation from all the participants, this study suggests on developing more men friendly $\mathrm{MCH}$ care settings and improves service delivery that routinely involves men. The current female oriented awareness programs in family planning and reproductive health should be re-examined and modified to involve men. In addition, effective implementation of men involvement in reproductive health initiatives should address the barriers and challenges to men's supportive participation in reproductive health. Furthermore, this study recommends on increasing literacy of reproductive health among men either by including it in the school curriculum or through any awareness activities that enhance their positivity and motivates them to participate in reproductive health services.

\section{Acknowledgment}

The authors would like to acknowledge all the participants for their contribution to the study by providing genuine information.

\section{Disclosure}

The authors report no conflicts of interest in this work.

\section{References}

1. Hogan MC, Foreman KJ, Naghavi M, et al. Maternal mortality for 181 countries, 1980-2008: a systematic analysis of progress towards Millennium Development Goal 5. Lancet. 2010;375(9726): $1609-1623$.

2. Shrestha S, Bell JS, Marais D. An analysis of factors linked to the decline in maternal mortality in Nepal. PLoS One. 2014;9(4):e93029.

3. World Health Organization (WHO). WHO recommendations on health promotion interventions for maternal and newborn health [Internet]; 2015. Available from: http://apps.who.int/iris/bitstr eam/10665/172427/1/9789241508742_report_eng.pdf. Accessed November 30, 2017.

4. Bishwajit G, Tang S, Yaya S, et al. Factors associated with male involvement in reproductive care in Bangladesh. BMC Public Health. 2017; 17(1):3.

5. World Health Organization. Policy approaches to engaging men and boys in achieving gender equality and health equity [Internet]; 2010. Available from: http://apps.who.int/iris/bitstream/handle/10665/44402/9789241500128_eng.pdf;jsessionid=8BF11008848 5BC317E333F0AE3C2E2E9? sequence=1.

6. Ampt F, Mon MM, Than KK, et al. Correlates of male involvement in maternal and newborn health: a cross-sectional study of men in a peri-urban region of Myanmar. BMC Pregnancy Childbirth. 2015;15(122):1-11.

7. Yargawa J, Leonardi-Bee J. Male involvement and maternal health outcomes: systematic review and meta-analysis. J Epidemiol Community Health. 2015;69(6):604-612.

8. Bhatta DN. Involvement of males in antenatal care, birth preparedness, exclusive breast feeding and immunizations for children in Kathmandu, Nepal. BMC Pregnancy Childbirth. 2013;13(1):14.

9. Lewis S, Lee A, Simkhada P. The role of husbands in maternal health and safe childbirth in rural Nepal: a qualitative study. BMC Pregnancy Childbirth. 2015;15(1):1-10.

10. Osamor PE, Grady C. Women's autonomy in health care decisionmaking in developing countries: a synthesis of the literature. Int $J$ Womens Health. 2016;8:191-202.

11. Kululanga LI, Sundby J, Malata A, Chirwa E. Striving to promote male involvement in maternal health care in rural and urban settings in Malawi - a qualitative study. BMC Reprod Heal. 2011;8(36).

12. Tokhi M, Comrie-Thomson L, Davis J, Portela A, Chersich M, Luchters S. Involving men to improve maternal and newborn health: A systematic review of the effectiveness of interventions. PLoS One. 2018;13(1):e0191620.

13. Kura S, Vince J, Chivers-Crouch P. Male involvement in sexual and reproductive in the Mendi district, Southern Highlands provinve of Papua New Guinea: a descriptive study. BMC Reprod Heal. 2013;10:93-100.

14. Kabagenyi A, Jennings L, Reid A, Nalwadda G, Ntozi J, Atuyambe L. Barriers to male involvement in contraceptive uptake and reproductive health services: a qualitative study of men and women's perceptions in two rural districts in Uganda. BMC Reprod Heal. 2014;11(21):1-9.

15. Singh A, Ram F. Men's involvement during pregnancy and childbirth: evidence from rural Ahmadnagar, India. Popul Rev. 2009;48(1):83-102.

16. Char A. Male Involvement in Family Planning and Reproductive Health in Rural Central India [Internet]. University of Tampere, School of Health Sciences; 2011. Available from https://tampub.uta.fi/bitstream/ handle/10024/66834/978-951-44-8658-6.pdf. cited 2018 May 23.

17. Shattuck D, Kerner B, Gilles K, Hartmann M, Ng T, Guest G. Encouraging contraceptive uptake by motivating men to communicate about family planning: the Malawi Male Motivator Project. 2008;101(6):1089-1095.

18. Exner TM, Mantell JE, Adeokun LA, et al. Mobilizing men as partners: the results of an intervention to increase dual protection among Nigerian men. 2009;24(5):846-854. 
19. Solórzano I, Bank A, Peña R, Espinoza H, Ellsberg M, Pulerwitz J. Catalyzing Personal and Social Change Around Gender, Sexuality and HIV: Impact Evaluation of Puntos de Encuentro's Communication Strategy in Nicaragua. Managua: Puntos de Encuentro; 2008.

20. Davis J, Luchters S, Holmes W. Men and Maternal and Newborn Health: Benefits, Harms, Challenges and Potential Strategies for Engaging Men. Melbourne: Compass: Women's and Children's Health Knowledge Hub; 2013.

21. Kaye DK, Kakaire O, Nakimuli A, Osinde MO, Mbalinda SN, Kakande $\mathrm{N}$. Male involvement during pregnancy and childbirth: men's perceptions, practices and experiences during the care for women who developed childbirth complications in Mulago Hospital, Uganda. $B M C$ Pregnancy Childbirth. 2014;14(1):1-8.
22. Davis J, Vyankandondera J, Luchters S, Simon D, Holmes W. Male involvement in reproductive, maternal and child health: a qualitative study of policymaker and practitioner perspectives in the Pacific. Reprod Health. 2016;13(1):1-11.

23. Ditekemena J, Koole O, Engmann C, et al. Determinants of male involvement in maternal and child health services in sub-Saharan Africa: a review. Reprod Health. 2012;9(1):1-8.

24. Hurst TE, Semrau K, Patna M, Gawande A, Hirschhorn LR. Demandside interventions for maternal care: evidence of more use, not better outcomes. BMC Pregnancy Childbirth. 2015;15(1):297.

25. Bowser D, Gupta J, Nandakumar A. The effect of demand- and supplyside health financing on infant, child, and maternal mortality in low- and middle income countries. Health Sys Reform. 2016;2(2):147-159.
Journal of Multidisciplinary Healthcare

\section{Publish your work in this journal}

The Journal of Multidisciplinary Healthcare is an international, peerreviewed open-access journal that aims to represent and publish research in healthcare areas delivered by practitioners of different disciplines. This includes studies and reviews conducted by multidisciplinary teams as well as research which evaluates the results or conduct of such teams or health care processes in general. The journal covers a very wide range of areas and welcomes submissions from practitioners at all levels, from all over the world. The manuscript management system is completely online and includes a very quick and fair peer-review system. Visit http://www.dovepress.com/ testimonials.php to read real quotes from published authors. 